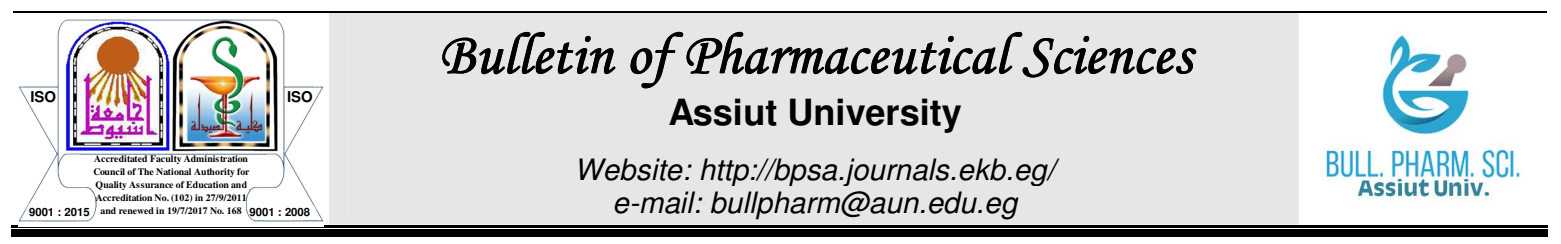

\title{
HOW DOES QUINOLONES ANTIBOTIC RESISTANCE DEVELOP?
}

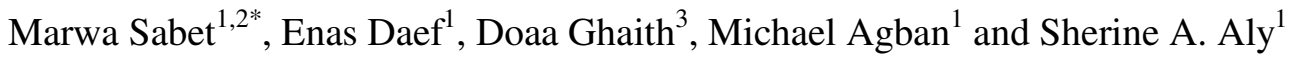 \\ ${ }^{1}$ Department of Medical Microbiology and Immunology, Faculty of Medicine, Assiut \\ University, Assiut, Egypt \\ ${ }^{2}$ Ministry of Health and Population, Assiut, Egypt \\ ${ }^{3}$ Department of Clinical and Chemical Pathology, Faculty of Medicine, Cairo University, \\ Cairo, Egypt
}

\begin{abstract}
The quinolone antibiotics arose in the early 1960s, with the first example having a narrow spectrum of activity with unfavourable pharmacokinetics. Over time, the development of new quinolone antibiotics has led to improved equivalents with an expanded spectrum and high efficacy. Nowadays, quinolones are broad-spectrum antibiotics that are active against both Gram-positive and Gram-negative bacteria, as well as mycobacteria, and anaerobes. They exert their actions by inhibiting bacterial nucleic acid synthesis through disrupting the enzymes topoisomerase IV and DNA gyrase, and by causing damage of bacterial chromosomes. Acquired bacterial resistance to quinolones rises due to the abuse of these drugs. Mechanisms contributing to quinolone resistance are mediated by chromosomal mutations and/or plasmid gene uptake that modify topoisomerase targets, modify the quinolone, and/or reduce drug accumulation by either decreased uptake or increased efflux. This review describes the history of development of this class of antibiotics, different generations, mechanism of action, along with the resistance mechanisms which reduce the quinolones' activities against different microorganisms.
\end{abstract}

\section{INTRODUCTION}

Quinolones are a group of synthetic antibacterial with major clinical importance, being one of the most frequently prescribed classes of antimicrobial agents in the world. Initially, quinolones were mostly used in the treatment of Gram-negative infections, but they were later modified in order to improve their pharmacokinetic properties and extend their antibacterial spectrum, becoming effective against a wide variety of Gram-negative and Gram-positive pathogens ${ }^{1-3}$.

The founding member of the quinolone drug class, Nalidixic acid, was introduced into clinical use in 1962 to treat uncomplicated urinary tract infections and can be considered as the first generation of the quinolones The discovery of nalidixic acid in 1962, and its introduction for clinical use in 1967, marks the beginning of six decades of quinolone development and use (Fig. 1) ${ }^{4 \& 5}$. Quinolones became a widely used drug class in the 1980s with the development of a second generation of compounds, the fluoroquinolones, which displayed considerably improved activity, greater Gram-positive penetration and enhanced pharmacokinetic and pharmacodynamic properties ${ }^{6 \& 7}$.

The most important modifications to the quinolone structure were the introduction of a fluorine at the sixth position and a major ring substituent at position seven. The first representative of this generation was Norfloxacin; however, Ciprofloxacin was the first fluoroquinolone that showed significant activity outside the urinary tract ${ }^{7}$. After more than 20 years in clinical use, Ciprofloxacin remains one of the most commonly prescribed antimicrobial drugs, being listed by the World Health Organization as an essential medicine and a critically important antibiotic that is used

Received in 5/3/2020 \& Accepted in 15/3/2020 


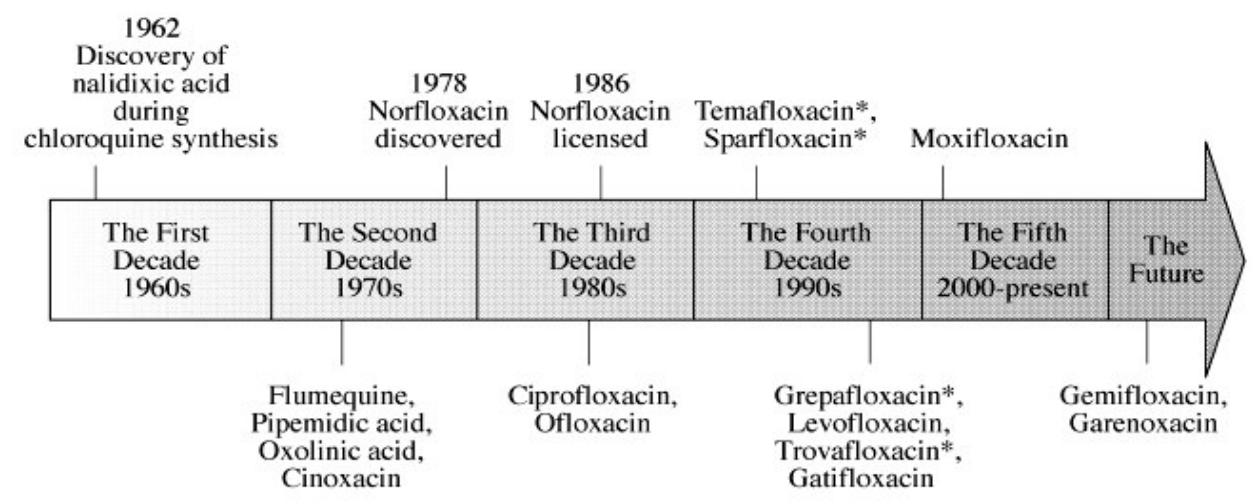

Fig. 1: Quinolones, decades of discovery and development ${ }^{5}$.

to treat a variety of Gram negative and to a lesser extent Gram positive infections. The clinical success of Ciprofloxacin led to the development of a collection of newergeneration quinolones (Levofloxacin, Moxifloxacin, Gatifloxacin) with an even broader and different spectrum of activity and pharmacokinetic characteristics ${ }^{8 \& 9}$.

\section{Quinolones generations}

Based on their antibacterial spectra, quinolone drugs are classified into 4 generations, (Table 1$)^{10}$. Chemical modifications of the quinolone nucleus resulted in the first-generation quinolones Pipemidic acid, Oxolinic acid and Cinoxacin, but these drugs were limited by their lack of efficacy against Gram-positive and anaerobic Gramnegative bacteria due to their low tissue and serum kinetics ${ }^{2}$. The second generation of quinolones started with fluoroquinolones obtained by fluoridation of the quinolone molecule at position C6. The Flumequine was the first fluoroquinolone which was patented in 1973, after that many fluoroquinolones have been patented, including norfloxacin (1978), Pefloxacin (1979), Enoxacin (1980), Fleroxacin (1981), Ciprofloxacin (1981) and Ofloxacin (1982). An advantage of these compounds over previous ones is their broad spectrum $^{11}$.

Fluoroquinolone drugs are active against a wide range of Gram negative and Grampositive pathogens and show improved oral absorption and systemic distribution. However, this second generation of quinolones has limited activity against limited number of clinically relevant Gram-positive bacteria and anaerobes $^{12}$. In the third generation of quinolones, more potent fluoroquinolones were developed, such as Levofloxacin, Gatifloxacin and Moxifloxacin, which exhibit improved bactericidal activity against Gram-positive bacteria. The fourth generation of quinolone drugs, such as Gemifloxacin, shows good activity against Gram-positive cocci and significant activity against anaerobes ${ }^{13}$.

\section{Mechanisms of quinolone action}

Quinolones act by inhibiting the activity of two essential bacterial type II topoisomerase enzymes, DNA gyrase and topoisomerase IV, which are involved in the modulation of the chromosomal supercoiling required for DNA synthesis, transcription, and cell division. Both enzymes are heterodimers with two subunits, gyrase is formed of GyrA2 and GyrB2 and topoisomerase IV as Par C2, Par E2. Gyr A is homologous to Par $C$ and Gyr B homologous to Par $E$ (Fig. 2) ${ }^{14 \& 15}$. These enzymes modulate DNA topology by passing an intact double helix through a transient 4-bp staggered double-stranded break that they introduce in a separate segment. In order to preserve genomic integrity during this process, DNA gyrase and topoisomerase IV form covalent bonds between active site tyrosine residues and the 5'overhangs at the DNA break, forming enzymecleaved DNA complexes known as cleavage complexes. Quinolones interfere with this critical process by reversibly binding to these cleavage complexes at the enzyme-DNA interface in the cleavage-ligation active site, therefore increasing the steady-state concentration of cleavage complexes by physically blocking DNA strand re-ligation ${ }^{2}$. 
Table 1: Fluoroquinolones are classified into four generations based on their pharmacokinetic profile and antimicrobial activity ${ }^{10}$.

\begin{tabular}{|l|l|l|l||}
\hline \multicolumn{1}{|c|}{ Generation } & \multicolumn{1}{|c|}{ Examples } & Pharmacokinetic profile & Antimicrobial activity \\
\hline First generation & $\begin{array}{l}\text { Nalidixic acid (NA), } \\
\text { Oxolinic acid (OA), } \\
\text { Cinoxacin (CIN), }\end{array}$ & High toxicity & Gram negative bacteria. \\
\hline $\begin{array}{l}\text { Second } \\
\text { generation }\end{array}$ & $\begin{array}{l}\text { Enoxacin (ENO), } \\
\text { Fleroxacin (FLE), } \\
\text { Ofloxacin (OFL), } \\
\text { Ciprofloxacin (CIP), } \\
\text { Norfloxacin (NOR), } \\
\text { Levofloxacin (LEV), } \\
\text { Lomefloxacin (LOM) }\end{array}$ & $\begin{array}{l}\text { Well tolerated and safe } \\
\text { fluoroquinolones }\end{array}$ & $\begin{array}{l}\text { Gram negative and } \\
\text { Pseudomonas species. }\end{array}$ \\
\hline Third generation & $\begin{array}{l}\text { Tosufloxacin (TOS), } \\
\text { Gatifloxacin (GAT), } \\
\text { Temafloxacin (TEM), } \\
\text { Grepafloxacin (GRE), } \\
\text { Sparfloxacin (SPA) }\end{array}$ & Broad spectrum activity & $\begin{array}{l}\text { Gram negative, gram } \\
\text { positive and atypical } \\
\text { bacterial strain. }\end{array}$ \\
\hline Fourth generation & $\begin{array}{l}\text { Clinafloxacin (CLI), } \\
\text { Gemifloxacin (GEM), } \\
\text { Sitafloxacin (SIT), } \\
\text { Moxifloxacin (MOX), } \\
\text { Trovafloxacin (TRO), } \\
\text { Ulifloxacin (ULI), } \\
\text { Besifloxacin (BES) }\end{array}$ & Efficient antibacterial & $\begin{array}{l}\text { Gram negative, gram } \\
\text { positive, pseudomonas, } \\
\text { aerobic and atypical } \\
\text { strains. }\end{array}$ \\
\hline
\end{tabular}

\section{Quinolone-topoisomerase interactions}

Specific mutations in gyrase or topoisomerase IV cause quinolone resistance suggest that drug protein interactions play important role in stabilizing cleavage complexes. The amino acids frequently associated with quinolone resistance is Ser83 and the acidic residue four amino acids downstream ${ }^{16}$.

Quinolones are known to target DNA gyrase and topoisomerase IV with varying efficiencies in different bacterial species. Generally, DNA gyrase is considered the primary target of quinolones in Gram-negative species and topoisomerase IV the primary target in Gram-positives ${ }^{17}$. However, the relative contribution of each topoisomerase to quinolone action still needs further investigation, on a species-by-species and drugby-drug basis. The formation of quinolonetopoisomerase-DNA ternary complexes causes the DNA replication machinery to become arrested at blocked replication forks, resulting in an inhibition of DNA synthesis, which immediately leads to bacteriostasis (at low quinolone concentrations) and eventually to cell death (at lethal concentrations) ${ }^{18}$.

\section{Mechanisms of quinolone resistance}

Due to the extensive use of these drugs in human and veterinary medicine, and despite prescribing guidelines now recommending reserving quinolone use, the number of quinolone-resistant strains has been growing steadily and quinolone use has been compromised by the emergence of resistance, having serious implications in some clinical settings ${ }^{2 \& 19}$. The acquisition of quinolone resistance may be associated with three types of mechanisms in descending order (Fig. 3) ${ }^{17}$ (a) chromosomal mutations that alter the target enzymes and their drug-binding affinity; (b) plasmid-acquired resistance genes producing either target protection proteins, drug modifying enzymes or drug efflux pumps and (c) chromosomal mutations leading to reduced drug accumulation by either decreased uptake or increased efflux ${ }^{20}$. The cellular alterations associated with each mechanism are not mutually exclusive and can accumulate to create high levels of quinolone resistance ${ }^{3,19 \& 21}$. 

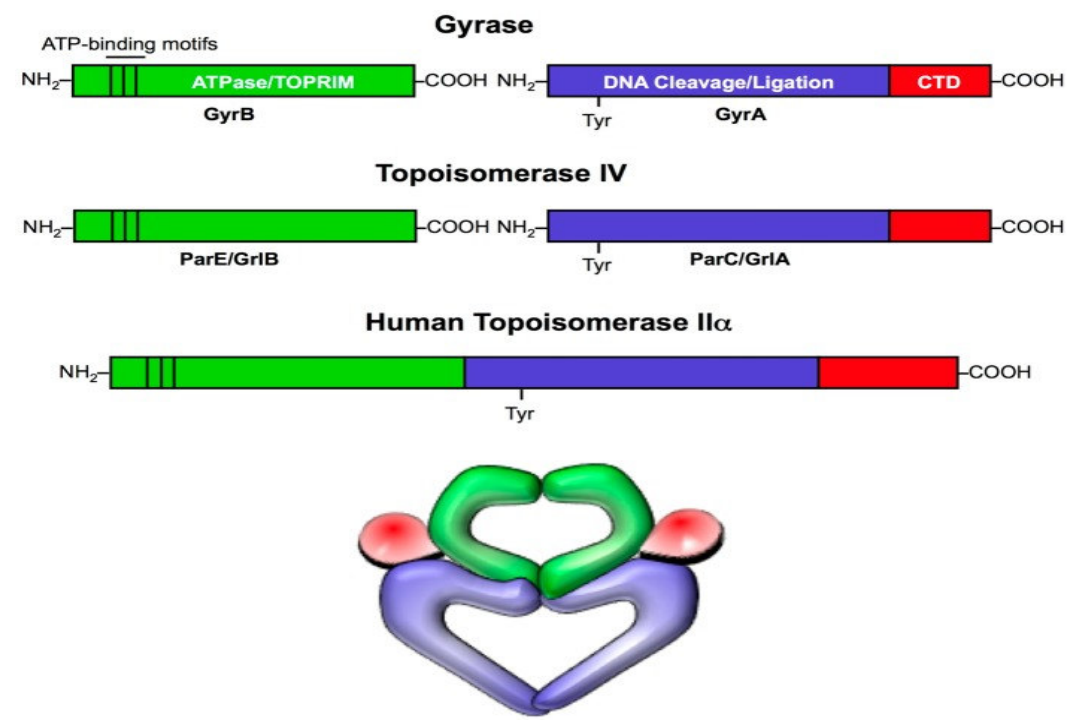

Fig. 2: Domain structures of type II topoisomerases. Gyrase and topoisomerase IV are heterotetrameric enzymes consisting of two A subunits and two B subunits. The A subunits (blue) contain the active site tyrosine residue that covalently attaches to the newly generated 5'-termini of DNA during the cleavage reaction. The C-terminal domains (CTDs; red) of the A subunits are variable and allow gyrase to introduce negative supercoils into DNA. The B subunits (green) contain the ATPase and TOPRIM domains, the latter of which binds the catalytic divalent metal ions essential for enzyme activity. A representation of the threedimensional structure of type II topoisomerases is shown at the bottom ${ }^{15}$.

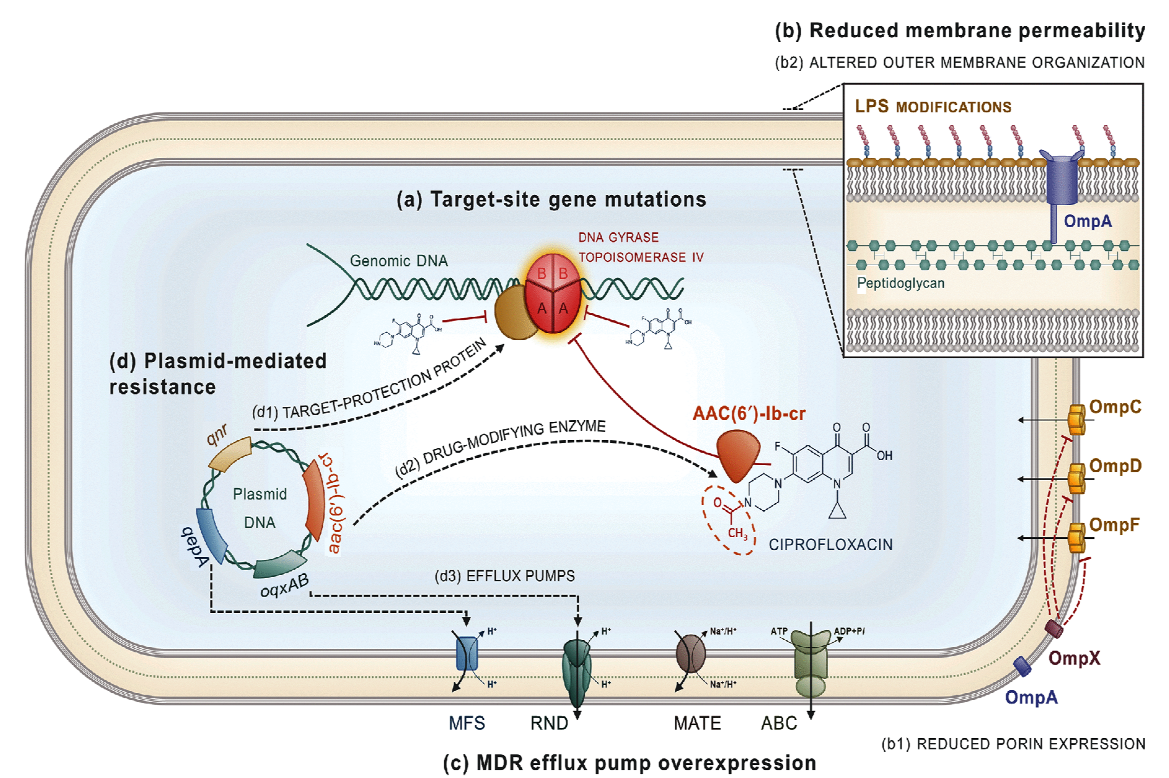

Fig. 3: Mechanisms of quinolone resistance ${ }^{20}$. (a) Chromosomal mutations within the QRDRs: of the genes encoding the A and B subunits of DNA gyrase and topoisomerase IV structurally change the target protein, reducing its drug-binding affinity. (b) Chromosomal mutations: leading to reduced outer membrane permeability, by either reduced porin expression (b1) or modifications in the outer membrane organization (b2), and also mutations leading to an increased expression of efflux pumps. (c) Efflux pumps that contribute additively to resistance by decreasing cytoplasmic quinolone accumulation. (d) Plasmid-encoded quinolone resistance genes can produce Qnr target-protection proteins (d1), AAC (6ф)-Ib-cr acetyltransferase variants capable of modifying certain quinolones (d2) or QepA and OqxAB efflux pumps that actively extrude quinolones (d3). LPS, lipopolysaccharide; MFS, major facilitator superfamily; RND, 
resistance-nodulation-division; MATE, multiple antibiotic, and toxin extrusion; ABC, ATP-binding cassette; MDR, multidrug resistance.

\section{a) Target-site gene mutations in type II} topoisomerases

The most common mechanism of highlevel resistance is due to mutations within the quinolone resistance-determining regions (QRDRs) of at least one of the genes that encode the primary and secondary targets of these drugs, the type II topoisomerases ( $g y r A$, gyrB, parC and parE). Mutations in the QRDRs of these genes result in amino acid substitutions that structurally change the target protein and, subsequently, the drug-binding affinity of the enzyme $e^{20 \& 22}$.

However, Resistance mutations in the GyrB and ParE subunits are less frequent than those in GyrA and ParC. The serine and acidic residues that anchor the water-metal ion bridge are the most common single amino acid substitutions that confer quinolone resistance as the disruption of this topoisomerasequinolone interaction is the cause of resistance in more than $90 \%$ of the mutant pools; despite, mutations have been found throughout the A and $B$ subunits of DNA gyrase and topoisomerase IV in quinolone-resistant strains. The magnitude of resistance caused by single amino acid changes in a DNA gyrase or topoisomerase IV subunit varies depending on the quinolone and the bacterial species, being the resistance phenotype of a particular mutation determined by the relative sensitivities of each enzyme to a particular quinolone $e^{2,3 \& 20}$.

The susceptibility of a wildtype isolate is determined by the more sensitive of the two target enzymes and, therefore, under quinolone selection pressure, resistance mutations will first occur in the more sensitive primary target, as mutation of the secondary less sensitive target alone is not enough for resistance due to dominance of the quinolone-primary target interaction. Therefore an accumulation of mutations in one or both target enzymes has been shown to cause increasing levels of quinolone resistance and it is generally accepted that high levels of quinolone resistance require double GyrA mutations; however, high-level resistance phenotypes have been reported with single GyrA mutations ${ }^{3 \& 23}$.
Single amino acid changes in either gyrase or topoisomerase IV can cause quinolone resistance. These resistance mutations in the QRDR have most commonly been localized to the amino terminal domains of GyrA (residues 67 to 106 for Escherichia coli numbering) or $\operatorname{ParC}$ (residues 63 to 102) and are in proximity to the active site tyrosines (Tyr122 for GyrA, Tyr120 for $\operatorname{ParC}$ ), which are covalently linked to DNA in an enzyme intermediate, in both enzymes $^{24}$. The most common site of mutation in GyrA of E. coli is at Ser83 followed by Asp87, with similar predominance of mutations at equivalent positions in other species ${ }^{2}$.

\section{b) Plasmid-mediated quinolone resistance (PMQR)}

Quinolone resistance also occurs via plasmid-mediated mechanisms, in addition to resistance caused by mutations in the bacterial genome. Plasmids carrying the quinolone resistance genes can cause serious clinical issues, with 10-250-fold decreases in susceptibility. The transmission of these resistance plasmids is through either horizontal transfer from bacteria to bacteria or vertical transfer from generation to generation ${ }^{25}$. Three reported gene families are involved in this plasmid-mediated quinolone resistance as demonstrated in table $2^{26}$.

Mechanisms involving PMQR were first described in the late 1990s and the first PMQR gene, qnrA, was described in 1998 in a broadhost-range conjugative plasmid of a ciprofloxacin-resistant Klebsiella. pneumoniae clinical isolate ${ }^{27}$. Plasmid-mediated quinolone resistance (PMQRs) is mediated by the quinolone-resistance protein (QNR) later named QnrA1. It is a pentapeptide repeat family protein that protects the by physically protecting DNA gyrase and topoisomerase IV from quinolone inhibition ${ }^{28}$. A hundred Qnr variants have been identified classifies into seven Qnr proteins have been identified; QnrA, QnrB, QnrS, QnrC, QnrD, QnrVC and QnrE, with numerous genetic variants6. The second PMQR mechanism involves a mutant aminoglycoside-modifying enzyme (AAC $\left(6^{\prime}\right)$ $\mathrm{Ib}$-cr) that is capable of modifying certain 
quinolones, including Ciprofloxacin and Norfloxacin, by adding an acetyl group thereby

reducing their antibacterial activity ${ }^{29}$.

Table 2: The plasmid-mediated quinolone resistance genes ${ }^{(26)}$.

\begin{tabular}{|c|c|}
\hline \multicolumn{2}{|l|}{ qnr gene } \\
\hline$q n r S$ & DNA mimics \\
\hline$q n r B$ & \multirow{2}{*}{$\begin{array}{l}\text { Decreases binding of enzymes to DNA } \rightarrow \text { lowering the enzyme targets on the } \\
\text { chromosome }\end{array}$} \\
\hline qnrC & \\
\hline$q n r D$ & \multirow[t]{2}{*}{ Binds to the enzymes and inhibits the quinolones from entering the cleavage complexes } \\
\hline$q n r V C$ & \\
\hline \multicolumn{2}{|c|}{$a a c\left(6^{\prime}\right)-I b-c r$ include 2 mutations } \\
\hline Trp102Arg & Variant of aminoglycoside acetyltransferase \\
\hline Asp179Tyr & Acetylates the unsubstituted $\mathrm{N}$ of the $\mathrm{C}_{7}$ piperazine ring $\rightarrow$ decreases drug activity \\
\hline \multicolumn{2}{|c|}{ Plasmid-mediated quinolone efflux pumps } \\
\hline OqxAB & Increases efflux pump activity \\
\hline QepA & Decreases susceptibility to hydrophilic quinolones \\
\hline
\end{tabular}

A third mechanism for PMQR was added with the discovery of the plasmid-encoded quinolone efflux pumps QepA and OqxAB ${ }^{30 \& 31}$. QepA belongs to the major facilitator superfamily (MFS)and confers decreased susceptibility to hydrophilic fluoroquinolones, especially Ciprofloxacin, norfloxacin and Enrofloxacin. OqxAB belongs to the RND family and has a wide substrate specificity that beyond the quinolones, Ciprofloxacin, Norfloxacin, Nalidixic acid, Olaquindox and Flumequine, also include the antibiotics Tetracycline, Chloramphenicol and Trimethoprim $^{3}$. These multidrug-resistant efflux pump encrypted genes do not directly cause high levels of resistance to quinolones but can assist the development of mutations to topoisomerase enzymes by allowing the bacteria to adapt to low concentrations in quinolones inside the bacteria ${ }^{26}$.

PMQR determinants generally confer only low-level quinolone resistance that alone does not exceed the clinical breakpoint. However, in the presence of therapeutic levels of quinolones, $\mathrm{PMQR}$ provides a favourable background for selection of additional resistance mechanisms and hence for the emergence of high levels of fluoroquinolone resistance (FQR) as their main role appears to be facilitating the emergence and selection of resistant mutants, namely gyrA mutations, that lead to a higher level of $\mathrm{FQR}^{19 \& 20}$. c) Chromosomal mutations leading to reduced drug accumulation

Quinolones must cross the bacterial envelope and mutations that result in a reduction of the intracellular drug concentration, either by decreased uptake, increased efflux or a combination of both, can confer quinolone resistance ${ }^{2 \& 3}$. The Gramnegative outer membrane represents an additional permeability barrier for hydrophilic drugs which cannot diffuse into the cell due to the core region of lipopolysaccharide (LPS) and therefore rely on outer membrane porin channels to enter the cell. Mutations that result in either porin loss, porin downregulation or a modification of the size or conductance of the porin channel will result in a limited, substantially slower diffusion of quinolones and other drugs into the cell and consequently lead to low level bacterial antibiotic resistance ${ }^{25 \& 32}$.

The reduced or loss of expression of porins such as OmpF, OmpC, OmpD and OmpA has been implied in increased antibiotic resistance to quinolones and other drugs. Moreover, the overexpression of OmpX, which has been described as a down-regulator of porin expression, leads to a decreased expression of the OmpC, OmpD, OmpF, LamB and Tsx porins, resulting in an increased resistance to a variety of antibiotics, including quinolones $^{3 \& 20}$. 
Reduced influx due to porin or LPS modifications often acts together with basal or increased expression of active efflux transporters in reducing cytoplasmic quinolone concentrations, both contributing additively to resistance, as bacterial exposure to quinolones can select mutants that overexpress efflux pumps, usually as a result of mutations in regulatory proteins and less often as a result of mutations in the structural genes associated with quinolone inclusion in pump substrate profiles $^{3}$.

Mutations affecting quinolone uptake and efflux cause only low-level resistance (about four- to eightfold increases in inhibitory concentrations) and do not usually represent a major clinical problem in the absence of additional resistance mechanisms ${ }^{20 \& 33}$. Efflux pumps are involved in quinolone extrusion in both Gram-positive and Gram-negative bacteria. In Gram-positive species, the major facilitator superfamily (MFS) contains the largest number of efflux systems that include quinolones in their substrate profiles. Also, efflux pumps belonging to the multiple antibiotic and toxin extrusion and ATP-binding cassette families have also been shown to confer quinolone resistance in Gram-positive species $^{34}$.

In Gram-negative bacteria, the majority of efflux pumps involved in quinolone resistance are members of the resistance-nodulationdivision (RND) family, which are tripartite complexes formed by an inner membrane pump protein, an outer membrane channel protein and a periplasmic membrane fusion protein as AcrAB-TolC in E. coli, Salmonella spp., Enterobacter aerogenes and Enterobacter cloacae $^{21 \& 35}$.

Mutations conferring high-level quinolone resistance are often a mixture of both targetand efflux-related mutations, with the latter mutations enhancing the expression of efflux pump activity. The reduced quinolone influx acts in concert with increased efflux to generate a resistance phenotype through mechanisms involving the transcriptional and post-transcriptional regulation of both efflux systems and porins ${ }^{21}$.

\section{d) Selectivity of quinolones in targeting the bacterial cells}

In number of studies on the in-vitro selection of quinolone resistant strains of $\mathrm{S}$. pneumoniae, investigators have reported observing diverse frequencies of resistance selectivity among fluoroquinolones. It has been suggested that gatifloxacin and clinafloxacin possess potent antipneumococcal activities and select mutant strains less frequently than other fluoroquinolones because of their inhibition of DNA gyrase and topoisomerase IV, which occur at nearly the same levels in bacterial cells (dual-targeting property) $^{36}$. Conversely, it has been reported that the ease of resistance selectivity in S. pneumoniae correlated with the susceptibilities of the agents to the bacterial Nor A-type efflux system ${ }^{37}$.

\section{REFERENCES}

1- Dalhoff Axel, "Global Fluoroquinolone Resistance Epidemiology and implications for Clinical Use", Volume 2012 / Article. Interdisciplinary Perspectives on Infectious Diseases. doi.org/10.1155/2012 /976273 (2012).

2- K. J. Aldred, R. J. Kerns and N. Osheroff, "Mechanism of quinolone action and resistance", Biochemistry, 53 (10), 15651574 (2014). doi:10.1021/bi5000564.

3- D. C. Hooper and G. A. Jacoby, "Topoisomerase inhibitors: Fluoroquinolone mechanisms of action and resistance", Cold Spring Harbor Perspectives in Medicine, 6 (9), a025320 (2016). doi:10.1101/cshperspect. A 025320 .

4- G. Y. Lesher, E. J. Froelich, M. D. Gurett, J. H. Baily and R. P. Brundage, "1,8Naphthyridine derivatives. A new class of chemotherapeutic agents", J. Med. Pharm. Chem., 91, 1063-1065 (1962).

5- M. Emmerson and A. M. Jones, "The quinolones: decades of development and use", Journal of Antimicrobial Chemotherapy, 51 (1), 13-20 (2003), https://doi.org/10.1093/jac/dkg208.

6- Stein Gary, "The 4-quinolone antibiotics: Past, present, and future", Pharmacotherapy, 8, 301-314, November -December (1988), https://doi.org/10. 1002/j.1875-9114. 
7- V. T. Andriole, "The quinolones: Past, present, and future", Clin. Infect. Dis., 41 (2), S113-S119 (2005).

8- V. R. Anderson and C. M. Perry, "Levofloxacin: A review of its use as a high-dose, short-course treatment for bacterial infection", Drugs, 68, 535-565 (2008).

9- G. J. Noel, "A review of levofloxacin for the treatment of bacterial infections", Clin. Med. Ther., 1, 433-458 (2009).

10- V. Yadav and P. Talwar, "Repositioning of fluoroquinolones from antibiotic to anti-cancer agents: An underestimated truth", Biomedicine \& Pharmacotherapy, 111, 934-946 (2019).

11- H. Takahashi, H. Watanabe, T. Kuroki, Y. Watanabe and S. Yamai, "Identification of tet (B), encoding high-level tetracycline resistance, in Neisseria meningitides", Antimicrobial Agents Chemotherapy, 46, 4045-4046 (2002). 10.1128/AAC.46.12. 4045-4046.2002.

12- M. E. Levison and J. H. Levison, "Pharmacokinetics and pharmacodynamics of antibacterial agents", Infectious Disease Clinics of North America, 23 (4), 791-vii (2009).

13- A. Fàbrega, S. Madurga, E. Giralt and J. Vila, "Mechanism of action of and resistance to quinolones", Microbial Biotechnology, 2 (1), 40-61 (2009). doi:10.1111/j.1751-7915.

14- D. C. Hooper, "Bacterial topoisomerases, anti-topoisomerases, and antitopoisomerase resistance", Clin. Infect. Dis., 27, S54-S63 (1997).

15- Y. Pommier, E. Leo, H. Zhang and C. Marchand, "DNA topoisomerases and their poisoning by anticancer and antibacterial drugs", Chem. Biol., 17, 421433 (2010).

16- S. K. Morgan-Linnell, L. Becnel Boyd, D. Steffen and L. Zechiedrich, "Mechanisms accounting for fluoroquinolone resistance in Escherichia coli clinical isolates", Antimicrob. Agents Chemother., 53, 235241 (2009).

17- X.-S. Pan, J. Ambler, S. Mehtar and L. M. Fisher, "Involvement of topoisomerase IV and DNA gyrase as ciprofloxacin targets in Streptococcus pneumoniae", ibid., 40, 2321-2326 (1996).

18- B. M. Howard, R. J. Pinney and J. T. Smith, "4-Quinolone bactericidal mechanisms", Arzneimittel - Forschung, 43, 1125-1129 (1993).

19- M. H. Abdel-Rahim, O. EL-Badawy, S. Hadiya, E. A. Daef, S.-J. Suh, D. M. Boothe and S. A. Aly, "Patterns of fluoroquinolone resistance in enterobacteriaceae isolated from the Assiut University Hospitals, Egypt: A comparative study", Microb. Drug Resist., 25, 509-519 (2018). doi:10.1089/mdr. 2018.0249

20- X. Liu, D. M. Boothe, K. Thungrat and S. Aly, "Mechanisms accounting for fluoroquinolone multidrug resistance Escherichia coli isolated from companion animals", Vet. Microbiol., 161, 159-168 (2012).

21- S. Correia, P. Poeta, M. Hébraud, José Luis Capelo and Gilberto Igrejas, "Mechanisms of quinolone action and resistance: Where do we stand?", J. Med. Microbiol., 66, 551 (2017).

22- K. J. Aldred, S. A. McPherson, C. L. Jr. Turnbough, R. J. Kerns and N. Osheroff, "Topoisomerase IV-quinolone interactions are mediated through a watermetal ion bridge: Mechanistic basis of quinolone resistance", Nucleic Acids Res., 41, 4628-4639 (2013).

23- S. Correia, M. Hebraud, I. Chafsey, C. Chambon, D. Viala, et al., "Impacts of experimentally induced and clinically acquired quinolone resistance on the membrane and intracellular subproteomes of Salmonella Typhimurium DT104B", $\boldsymbol{J}$. Proteomics, 145, 46-59 (2016).

24- A. Wohlkonig, P. F. Chan, A. P. Fosberry, P. Homes, J. Huang, M. Kranz, V. R. Leydon, T. J. Miles, N. D. Pearson, R. L. Perera, A. J. Shillings, M. N. Gwynn and B. D. Bax, "Structural basis of quinolone inhibition of type IIA topoisomerases and target-mediated resistance", Nat. Struct. Mol. Biol., 17, 1152-1153 (2010).

25- J. Strahilevitz, G. A. Jacoby, D. C. Hooper and A. Robicsek, "Plasmid-mediated quinolone resistance: A multifaceted threat", Clin. Microbiol. Rev., 22, 664689 (2009). 
26- Thu D. M. Pham, Zyta M. Ziora and Mark A. T. Blaskovich, "Quinolone antibiotics", Med. Chem. Commun., 10, 1719-1739 (2019).

27- L. Martinez-Martinez, A. Pascual and G. A. Jacoby, "Quinolone resistance from a transferable plasmid", Lancet, 351, 797799 (1998).

28- G. A. Jacoby, J. Strahilevitz and D. C. Hooper, "Plasmid-mediated quinolone resistance", Microbiol. Spectr. 2 (5), 10.1128/ Microbiol Spec. PLAS-00062013 (2014). doi:10.1128/microbiolspec. PLAS-0006-2013.

29- A. Robicsek, J. Strahilevitz, G. A. Jacoby, M. Macielag, D. Abbanat, C. H. Park, K. Bush and D. C. Hooper", "Fluoroquinolone-modifying enzyme: A new adaptation of a common aminoglycoside acetyltransferase", Nat. Med., 12, 83-88 (2006).

30- A. H. Sorensen, L. H. Hansen, E. Johannesen and S. J. Sorensen, "Conjugative plasmid conferring resistance to olaquindox", Antimicrob. Agents Chemother., 47, 798-799 (2003).

31- K. Yamane, J. Wachino, S. Suzuki, K. Kimura, N. Shibata, H. Kato, K. Shibayama, T. Konda and Y. Arakawa, "New plasmid-mediated fluoroquinolone efflux pump, QepA, found in an Escherichia coli clinical isolate", ibid., 51, 3354-3360 (2007).

32- G. A. Jacoby, "Mechanisms of resistance to quinolones", Clin. Infect. Dis., 41(2), S120-S126 (2005).
33- S. A. Aly, N. Debavalya, S. J. Suh, O. A. Oryazabal and D. M. Boothe, "Molecular mechanisms of antimicrobial resistance in fecal Escherichia coli of healthy dogs Patterns of Fluoroquinolone Resistance after enrofloxacin or amoxicillin administration", Can. J. Microbiol., 58, 1288-1294 (2012).

34- D. C. Hooper and G. A. Jacoby, "Mechanisms of drug resistance: Quinolone resistance", Ann. N. Y. Acad. Sci., 1354 (1), 12-31 (2015). doi:10.1111/ nyas. 12830.

35- T. Yasufuku, K. Shigemura, T. Shirakawa, M. Matsumoto, Y. Nakano, K. Tanaka, S. Arakawa, S. Kinoshita, M. Kawabata and M. Fujisawa, "Correlation of overexpression of efflux pump genes with antibiotic resistance in Escherichia coli strains clinically isolated from urinary tract infection patients", J. Clin. Microbiol., 49, 189-194 (2011).

36- X.-S. Pan and L. M. Fisher, "DNA gyrase and topoisomerase IV are dual targets of clinafloxacin action in Streptococcus pneumoniae", Antimicrob. Agents Chemother., 42, 2810-2816 (1998).

37- R. Beyer, E. Pestova, J. J. Millichap, V. Stosor, G. A. Noskin and L. R. Peterson, "A convenient assay for estimating the possible involvement of efflux of fluoroquinolones by Streptococcus pneumoniae and Staphylococcus aureus: Evidence for diminished moxifloxacin, sparfloxacin, and trovafloxacin efflux", ibid., 44, 798-801 (2000). 
Bull. Pharm. Sci., Assiut University, Vol. 43, Issue 1, 2020, pp. 95-104.

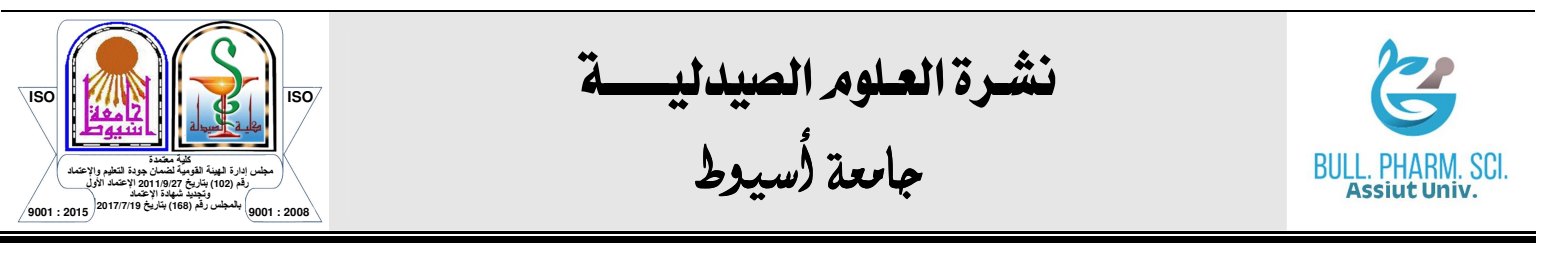

$$
\begin{aligned}
& \text { كيف تثكون المقاومة للمضادات الحيوية الكينولونات؟ } \\
& \text { مروة ثنابت '، - ايناس ضيف '- دعاء غيثج - مايكل عجبان' - شيرين على' } \\
& \text { 'قسم الميكروبيولوجيا و المناعة الطبية - كلية الطب - جامعة اسيوط ، أسيوط ، مصر }
\end{aligned}
$$

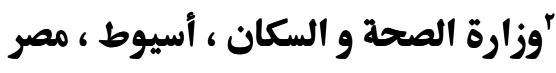

$$
\begin{aligned}
& \text { "قسم الباثولوجيا الإكلينيكية والكيميائية ، كلية الطب ، جامعة القاهرة ، القاهرة ، مصر }
\end{aligned}
$$

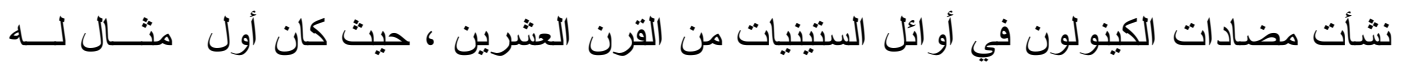

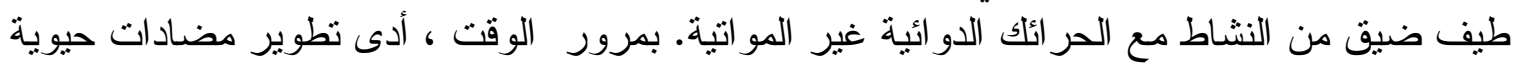

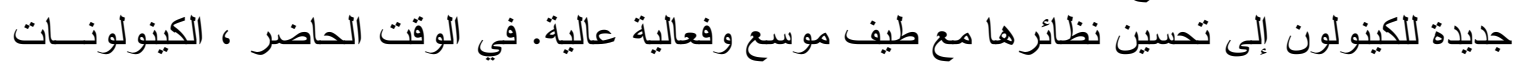

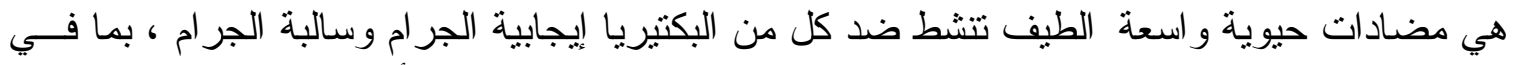

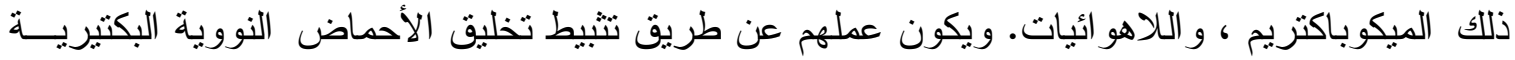

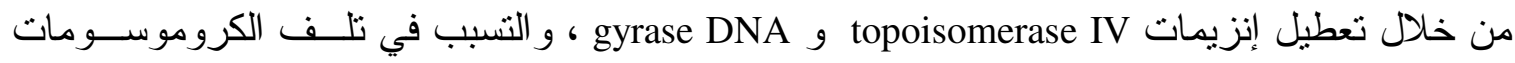
البكتيرية.

تتطور المقاومة البكتيرية المكتسبة للكينولونات بسبب إساءة استخدام هذه الأدوية. يتم التوسط

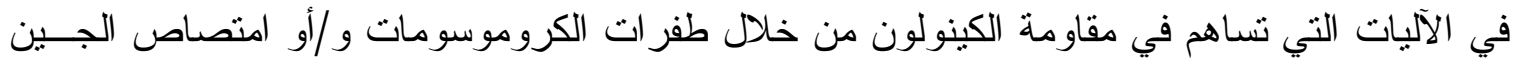

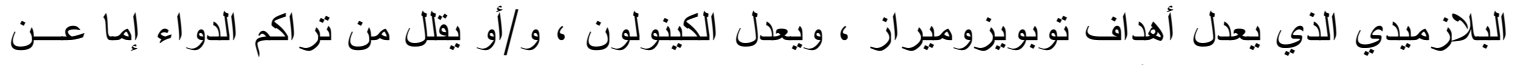

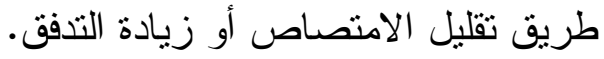

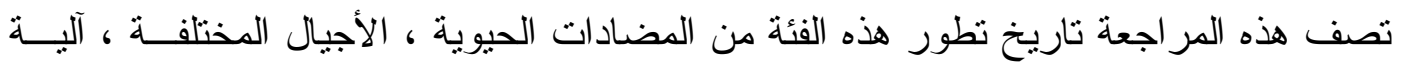

العمل ، إلى جانب آليات المقاومة التي تقلل أنشطة الكينولونات ضد ضد الكائنات الحية الدقيقة المختلفة. 